\title{
Valeriana Officinalis and Melissa Officinalis Extracts Normalize Brain Levels of GABA and Glutamate Altered by Chronic Stress
}

\author{
Francesco Scaglione $^{1 *}$ and Andrea Zangara ${ }^{2,3}$ \\ ${ }^{1}$ Department of Medical Biotechnology and Translational Medicine, University of Milan, Italy \\ ${ }^{2}$ Centre for Human Psychopharmacology, Swinburne University of Technology, Hawthorn, Australia \\ ${ }^{3}$ Natural Power Meds Consulting, Barcelona, Spain
}

*Corresponding author: Prof. Francesco Scaglione, MD, PhD, Department of Medical Biotechnology and Translational Medicine, University of Milan, Via Vanvitelli 32, 20129-Milan, Italy, Tel: ++39-0250317073, Fax: ++39-0250317050,

E-mail: francesco.scaglione@unimi.it

\begin{abstract}
Despite being traditionally used herbals to treat mild anxiety and sleep disorders, Valeriana officinalis and Melissa officinalis mechanism of action is not fully understood. While the pattern of mood modulation of both herbals suggests the involvement of the Gamma-Aminobutyric Acid (GABA) ergic system, other changes in the neurotransmitters pathways can provide an explanation for the clinical effects. The aim of this study was to examine the combined mechanism of action of the two extracts in order to explain the anxiolytic and calming effects that may facilitate sleep induction and improve sleep quality in patients with mild to moderate sleep disturbances. These effects have been previously reported in the literature for a botanical product combining $120 \mathrm{mg}$ Valeriana officinalis and $80 \mathrm{mg}$ of Melissa officinalis standardized extracts (Songha ${ }^{\circledR}$ Night). To assess mechanism of action we employed the Unpredictable Chronic Mild Stress (UCMS) animal model, as it has strong predictive validity. Brain GABA and glutamate levels were sampled using a microdialysis technique and measured by HPLC. Additional in vitro experiments investigated the effects of the extracts on Group II Metabotropic Glutamate Receptors (mGlu2) binding and GABA Transaminase (GABA-T) activity. Results indicate that the two extracts together exert a functional synergism leading to normalization of brain levels of GABA and glutamate altered by stress. In vitro experiments reveal that the combination of both extracts could inhibit GABA-T activity more effectively than the single extracts, and that Valeriana officinalis binds mGlu2 receptors. Altogether these results demonstrate a synergistic effect of Valeriana officinalis and Melissa officinalis standardized extracts on counteracting the alterations in neurotransmitter levels caused by chronic stress and support the tranquilizing and sleep inducing activity of Songha ${ }^{\circledR}$ Night observed in clinical trials.
\end{abstract}

\author{
Keywords \\ Valeriana officinalis, Melissa officinalis, GABA, Glutamate, \\ Sleep
}

\section{Introduction}

Sleep loss and sleep disorders are among the most common health problems. Surveys report that approximately $30 \%$ to $40 \%$ of adults have problems initiating or maintaining sleep [1-3]. About $10 \%$ to $15 \%$ of adults report severe problems, and this statistic rises up to $25 \%$ in the elderly [2]. Insomnia is found in up to $69 \%$ of patients attending primary care clinics and more common with chronic medical conditions $[3,4]$. Chronic sleep loss has serious consequences for health, performance, and safety [5]. Anxiety and stress disorders represent a range of conditions that include generalized anxiety, panic attacks, post-traumatic stress disorder, obsessive-compulsive syndrome, and social phobias. All of them lead to sleep disturbances and interfere with cognitive functions [6]. Unfortunately, there is only limited evidence to support the efficacy of many of the commonly used remedies for insomnia, including antihistamines, chloral hydrate, barbiturates, tryptophan, and melatonin [7]. Although benzodiazepines are known to be effective for insomnia, their clinical benefit is negligible and similar to that found with exercise therapy alone [8]. Moreover, benzodiazepine receptor agonists chronic treatment is limited by con-

Citation: Scaglione F, Zangara A (2017) Valeriana Officinalis and Melissa Officinalis Extracts Normalize Brain Levels of GABA and Glutamate Altered by Chronic Stress. J Sleep Disord Manag 3:016. doi.org/10.23937/25724053.1510016

Received: May 05, 2017: Accepted: September 16, 2017: Published: September 18, 2017

Copyright: (c) 2017 Scaglione F, et al. This is an open-access article distributed under the terms of the Creative Commons Attribution License, which permits unrestricted use, distribution, and reproduction in any medium, provided the original author and source are credited. 
cerns regarding long-term efficacy and the potential for abuse, dependence, and adverse side effects, including an increased risk of motor vehicle accidents, falls, and fractures [7]. For these reasons, many people with sleep disorders resort to complementary medicines, including herbal extracts [9].

Two herbal extracts, Valeriana officinalis (VAL) and Melissa officinalis (MEL) have been commonly used to treat mild anxiety and sleep disorders $[10,11]$. The extract of the root of VAL, a flowering plant, has been widely used to treat sleep disorders in Europe for decades [10] and is becoming increasingly popular in the United States as a self-prescribed treatment for insomnia. In a national survey, approximately two million adults reported using valerian in the past week [11].

The perennial lemon-scented herb MEL (synonym lemon balm) has been in use as a pan-cultural medicinal treatment for more than two millennia. Its traditional indications have included general beneficial effects on the brain as a treatment for memory disorders [12] and for "all complaints supposed to proceed from a disordered state of the nervous system" [13]. Contemporary reports emphasize the sedative, spasmolytic, and antibacterial effects of $\mathrm{MEL}$, with indications encompassing nervous, gastrointestinal, and sleep disorders [14-16].

The specific mechanisms of action responsible for the pharmacological effects of VAL and MEL have not been fully elucidated, nevertheless, accumulating evidence points towards both GABAergic and glutamatergic actions of both extracts [10,17-24].

While GABA receptor binding activity is relatively well studied in anxiolytic botanicals, one of the other mechanisms that induce GABA levels to increase in the brain and potentially cause anxiety reduction is the inhibition of the enzyme GABA-T [25-27].

Anxiety-related cognitive and behavioral disorders often result from low levels of the inhibitory neurotransmitter GABA [28] and an increased glutamate release [29].

A precise combination of $120 \mathrm{mg}$ VAL and $80 \mathrm{mg}$ MEL standardized extracts (Songha ${ }^{\circledR}$ Night) has been shown to improve sleep quality in patients with mild to moderate sleep disturbances and to have anxiolytic effects, with no decrease in vigilance or mental performance, no additive effect with alcohol in the psychomotor functioning, and rare or inconsistent hangover symptoms, $[30,31]$, as opposed to benzodiazepines and other sedative compounds. The neurotransmitters GABA and glutamate are both involved in the pathophysiology of sleep and mood disorders; published data point to an increase of glutamate release and a deficit of GABA [28, 29,32-34].

Hence, we tested the hypothesis that the combined mechanism of action of the two extracts contained in Songha ${ }^{\circledR}$ Night may induce a synergistic effect modulating the levels of GABA and glutamate in the Central
Nervous System (CNS). For this reason, we measured the levels of glutamate and GABA in the brain of rats exposed to chronic stress and treated with either VAL, or MEL, or a combination of both extracts. We selected the Unpredictable Chronic Mild Stress (UCMS) animal model, as most effects of UCMS can be reversed by antidepressant agents, illustrating a strong predictive validity [35].

\section{Materials and Methods}

\section{Animals}

Six to eight-week-old female Wistar rats were purchased from Charles River (Calco, Italy). Animals were left to acclimate for 1 week before entering the study. Rats were then divided in five groups (ten animals per group) and stressed using the UCMS technique. Institutional and national guide for the care and use of laboratory animals was followed (Prot. N. 15-2013).

\section{Materials}

MEL and VAL standardized extracts were supplied by Ginsana SA (Bioggio, Swizerland). The analytical markers for VAL are valerenic acids, and the fixed ratio herbal drug:dry extract $=4.5: 1$; while the MEL analytical marker is rosmarinic acid (> 1.8\%) and the extract is standardized on the fixed ratio herbal drug:dry extract $=5: 1$.

\section{Chemicals}

L-[3,4-3H]-Glutamic acid $(49.9 \mathrm{Ci} / \mathrm{mmol})$ was obtained from Perkin Elmer Life and Analytical Sciences, Inc. LCCG-I (2S,1S,2S)-2-(Carboxycyclopropyl)glycine and L-AP4 (L-(+)-2-Amino-4-phosphonobutyric acid) were obtained from Tocris Bioscience (Ellisville, MO). All other reagents were obtained from Sigma-Aldrich Co.

\section{Stress procedures}

The UCMS model involves the chronic sequential application of a variety of extremely mild stressors in a random order, so that they are unpredictable. The stress regimen is applied for three weeks. Different stressors are presented:

- Short periods ( $3 \mathrm{~h}$ ) of food and water deprivations

- Confinement in a small tube (1 h)

- Paired housing (exposure of a rat to another stressed rat in the same cage) ( $2 \mathrm{~h}$ )

- Reversal of the dark/light cycle

- $45^{\circ}$ tilt cage $(1 \mathrm{~h})$

- Forced swim (30 min)

- Housing with damp sawdust

- Access to an empty bottle (2 h).

\section{Experimental procedure}

Rats were divided in five groups. Each group of ten animals was treated as follows: 
1. Untreated and not stressed

2. Untreated and stressed

3. Treated with MEL (15 mg/kg) extract and stressed

4. Treated with VAL $(20 \mathrm{mg} / \mathrm{kg})$ extract and stressed

5. Treated with combination and stressed

Exact doses were established after preliminary experiments.

Treatment administration started one week after the beginning of the stress procedure and continued for two more weeks. After treatments, brain levels of glutamate and GABA were sampled using a microdialysis technique.

\section{Microdialysis}

For the microdialysis experiments, rats were anesthetized with Isoflurane $1.5-2 \% \mathrm{~V} / \mathrm{V}$ and placed in a Kopf stereotaxic frame. Intracerebral guide cannulae (OD 635 Im; ID 457 Im) provided by dialysis probe were implanted close to the lateral hippocampus and fixed to the skull. Dialysate samples were collected and frozen immediately on dry ice and were stored at $-70{ }^{\circ} \mathrm{C}$ before analysis.

\section{Assay of glutamate and GABA in the dialysate}

Analyses were carried out for both substances as previously described [35] by High-Performance Liquid Chromatography (HPLC) with laser-induced fluorimetric detection after o-phthalaldehyde derivatization with little changes. Briefly, an Ascentis Express C18, $100 \mathrm{~mm}$ $\times 4.6 \mathrm{~mm}, 2.7 \mu \mathrm{m}$ column was used. The mobile phase consisted of methanol-potassium acetate $(0.1 \mathrm{M})$ adjusted to $\mathrm{pH} 5.52$ with glacial acetic acid. A gradient (flow rate $0.9 \mathrm{~mL} / \mathrm{min}$ ) of three linear steps- from 25 $43 \%$ methanol ( $1 \mathrm{~min}$ ), from $43-70 \%$ methanol (10 $\mathrm{min}$ ) and from $70-90 \%$ ( $1 \mathrm{~min}$ ) - followed by an isocratic hold at $90 \%$ methanol (1 $\mathrm{min}$ ) and then back from $90-25 \%$ methanol (1 $\mathrm{min})$. One volume $(10 \mu \mathrm{L})$ of dialysate was mixed with $1 \mu \mathrm{L}$ of the o-phthalaldehyde derivatization reagent in a glass capillary tube and injected after 1.5 min. Standard curves were linear over the concentration range of $25-1000 \mathrm{fmol} / \mu \mathrm{L}$. The minimum detectable concentration was $3 \mathrm{fmol} / \mu \mathrm{L}$.

\section{GABA-T activity}

GABA-T activity was determined following the method of Sherif, et al. [36]. The extracts were tested in triplicate at final concentrations in the range 0.01-1000 $\mathrm{mg} / \mathrm{L}$ (in wells) in order to determine the EC50 concentration. The relative activity of each concentration was compared with the control, which was set to $100 \%$. One unit of enzyme activity was designated to the amount of enzyme activity that converts $1.0 \mu$ mole of GABA to succinic semialdehyde and then to succinate per minute with a stoichiometric reduction of $1.0 \mu$ mole of NADP ${ }^{+}$ at $\mathrm{pH} 8.6$ at $25^{\circ} \mathrm{C}$.

\section{Glutamate binding assay}

Receptor binding competition assays were performed using purified synaptosomes isolated from the ventral and the dorsal hippocampus. The reaction was initiated by the addition of tissue ( $100 \mu \mathrm{g}$ protein) to tubes containing $1 \mathrm{mM}$ of different lonotropic Glutamate Receptor (iGluR) and mGluR ligands and $20 \mathrm{nM} \mathrm{[3H]} \mathrm{Glutamic}$ acid in a final volume of $500 \mu \mathrm{L}$ of $50 \mathrm{mM}$ Tris- $\mathrm{HCl} / 100$ $\mathrm{mM} \mathrm{KCl}$ buffer, $\mathrm{pH}$ 7.4. The nonspecific binding was determined in the presence of $1 \mathrm{mM}$ nonradioactive glutamate. All samples were incubated on ice $\left(0-4^{\circ} \mathrm{C}\right)$ for 40 minutes. The assay was stopped by centrifugation for $30 \mathrm{~min}$ at 6,700 g; the supernatant was extracted and the pellet was washed two times with $1 \mathrm{~mL}$ of ice-cold buffer. The pellet was suspended in $500 \mu$ l of buffer. Radioactivity of the samples was quantified in a Beckman LS 6500 Multipurpose Scintillation Counter with $1 \mathrm{~mL}$ of Universal ES scintillation cocktail.

The mGluR ligands evaluated were LCCG-I (2S,1'S,2'S)2-(Carboxycyclopropyl)glycine and L-AP4 (L-(+)-2-Amino-4phosphonobutyric acid).

\section{Statistical analysis}

Data were analyzed using the univariate Analysis of Variance (one-way ANOVA), followed by Bonferroni t-test for multiple comparisons. Statistical significance was accepted when $\mathrm{p}<0.05$.

\section{Results}

To assess whether VAL and MEL were able to change the levels of GABA and glutamate in animals subjected to stress, rats were stressed with the UCMS procedure.

Brain levels of GABA and glutamate before and after

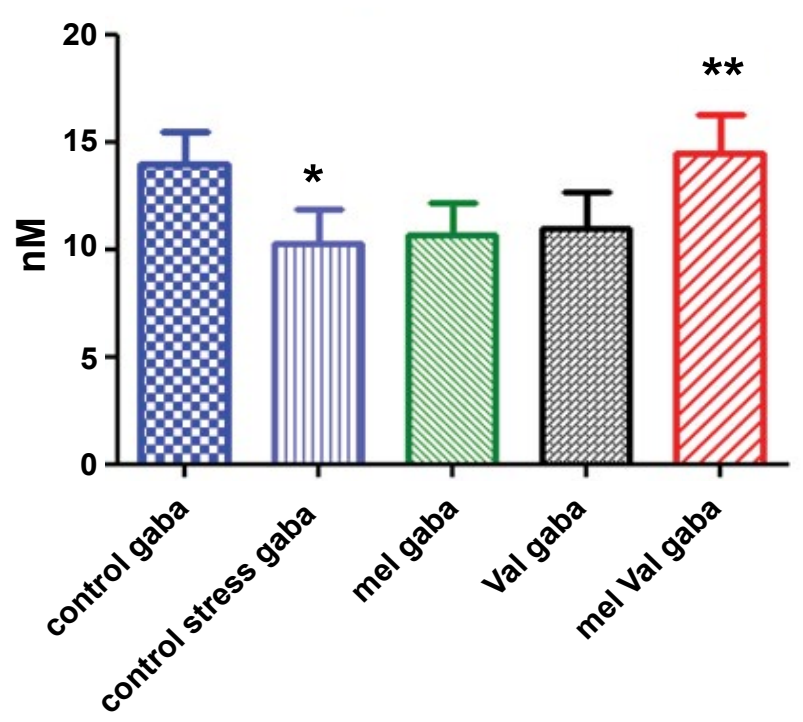

Figure 1: Brain concentration of GABA (nM) in stressed rats vs. control. Control $=$ untreated, unstressed; Control stress $=$ untreated, stressed; Mel = stressed, treated with M. officinalis; $\mathrm{Val}=$ stressed, treated with $V$. officinalis; $\mathrm{Mel}$ $\mathrm{Val}=$ stressed, treated with combination ( $\mathrm{p}<0.001 \mathrm{vs}$. control; " $p<0.001$ vs. control stress). 
UCMS chronic stress are shown in Figure 1 and Figure 2 respectively. Three weeks of stress decreased the brain levels of GABA significantly $(p<0.001)$. The treatment with MEL or VAL increased the level of GABA in treated rats compared to untreated stressed animals, but the comparison was not statistically significant. However, the combined treatment with both extracts produced significantly higher levels of GABA than untreated stressed animals $(p<0.001)$ as well as to stressed animals treated with MEL $(p<0.001)$ or VAL $(p<0.01)$. The combined treatment restored the brain levels of GABA at the same levels of unstressed animals.

Regarding glutamate brain levels, induced stress increased its levels significantly $(p<0.05)$. The treatment of VAL alone decreased the levels of glutamate significantly $(p<0.05)$ compared to untreated stressed animals, while MEL alone was ineffective. Surprisingly, the combination of the two extracts significantly decreased the levels of glutamate, compared both to stressed animals $(p<0.001)$ and to stressed animals treated with

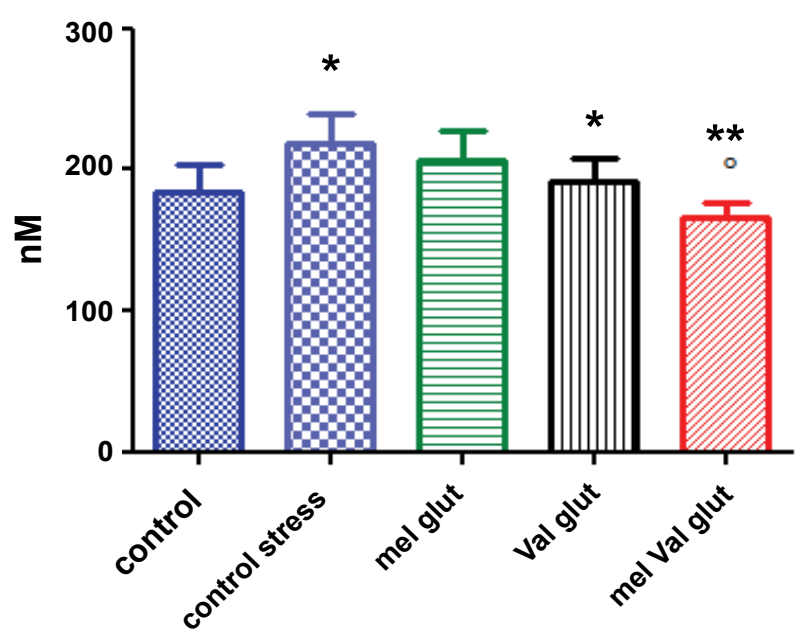

Figure 2: Brain concentration of glutamate (nM) in stressed rats vs. control. Control = untreated, unstressed; treated with $M$. officinalis; $V a l=$ stressed, treated with $V$. officinalis; Mel $\mathrm{Val}=$ stressed, treated with combination $\left({ }^{*}=p<0.05 \mathrm{vs}\right.$. control; ${ }^{* *}=p<0.001$ vs. control stress; ${ }^{\circ} p<0.05$ versus val glut).

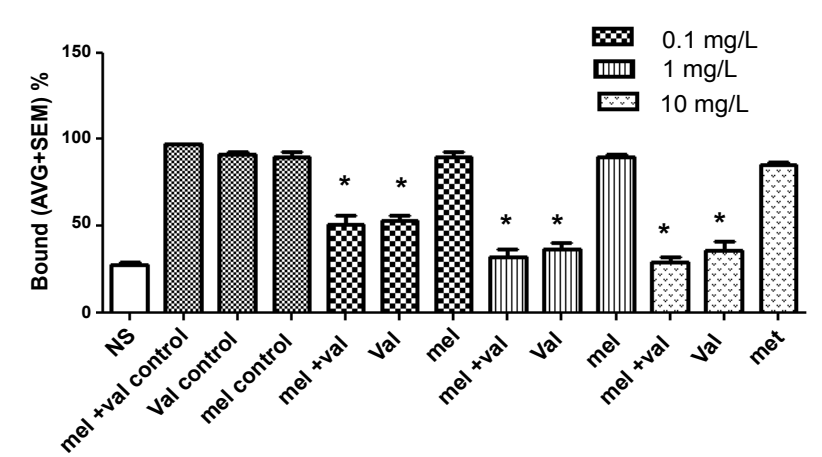

Figure 3: Interactions of $V$. officinalis (val), $M$. officinalis (mel), and its combination on metabotropic glutamate receptors (mGluR), in presence of LCGG, a Group II metabotropic glutamate receptor agonist. ( $p<0.01$ ).
VAL alone $(p<0.05)$. Also, in this case, the combined treatment restored brain levels of glutamate at levels similar to unstressed animals.

\section{Glutamate binding assay}

The effect of VAL and MEL extract concentrations were dose dependent in presence of $[3 \mathrm{H}]$ glutamate, as shown in Figure 3 and Figure 4. To test the hypothesis that VAL and/or MEL may reduce the brain levels of glutamate acting at presynaptic levels, binding assays were done in presence of different types of mGluR ligands.

VAL extract in presence of LCCG-I or L-AP4A Group II metabotropic glutamate receptor agonists decreased $[3 \mathrm{H}]$ glutamate binding, showing the ability to bind these receptors. No effects were observed with MEL extract alone or in combination (Figure 3 and Figure 4).

\section{GABA-T enzyme activity}

The inhibitory activity of MEL and VAL extracts on GABA-T is shown in Figure 5. The MEL extract inhibition was dose dependent and started at $5 \mu \mathrm{g} / \mathrm{ml}$. At the highest dose tested, it was close to $90 \%$. VAL extract shows about $30 \%$ inhibition at the highest concentration tested. Interestingly, the combination of MEL and VAL could inhibit GABA-T more effectively than MEL and VAL alone.

\section{Discussion}

The amount of both neurotransmitters GABA and glutamate and sleep or mood are striclty correlated: GABA has relaxing properties whereas glutamate shows excitatory effect [32-34].

Antidepressant and mood-stabilizing treatments appear to raise cortical GABA levels and ameliorate GABA deficits in patients with mood disorders; while acute stress is associated in preclinical studies with increased excitatory amino acid transmission in areas of the forebrain. Restraint stress, tail pinch, forced swimming, foot

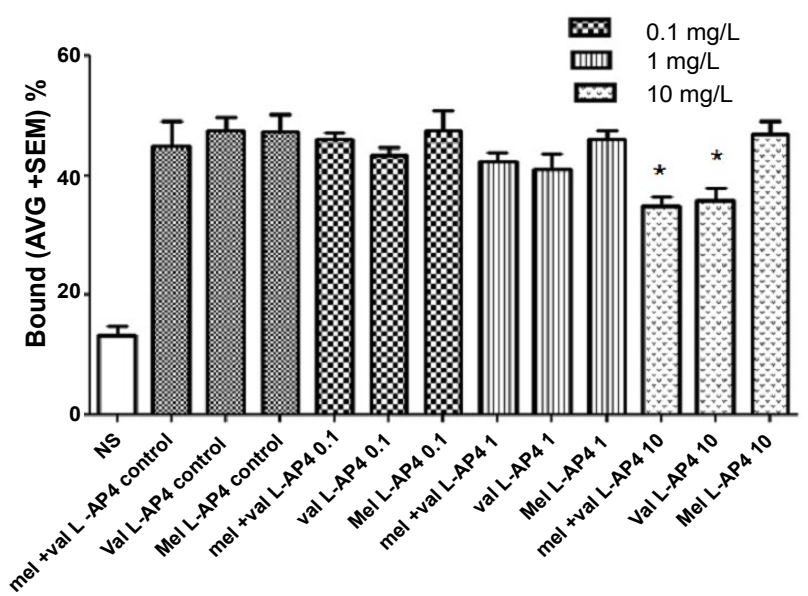

Figure 4: Interactions of $V$. officinalis (val), M. officinalis, and its combination on metabotropic glutamate receptors (mGluR), in presence of L-AP4, a Group II metabotropic glutamate receptor agonist. ( $\mathrm{p} p<0.01$ vs. control). 


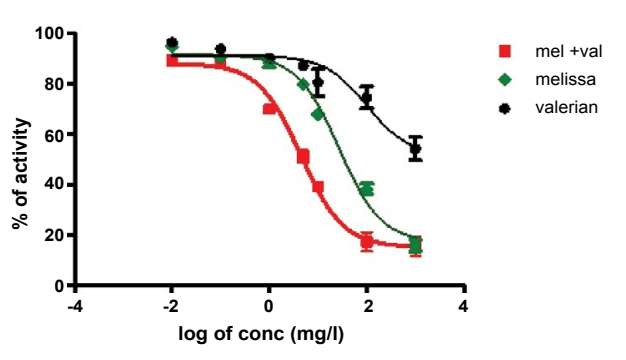

\begin{tabular}{|c|c|c|c|}
\hline & MEL+VAL & MEL & VAL \\
\hline \multicolumn{4}{|c|}{ Best-fit values } \\
\hline Bottom & 15.16 & 17.09 & 51.46 \\
\hline Top & 88.28 & 91.77 & 91.41 \\
\hline LogEC50 & 0.6511 & 1.438 & 2.009 \\
\hline EC50 & 4.478 & 27.39 & 102 \\
\hline \multicolumn{4}{|l|}{ Std. error } \\
\hline Bottom & 1.973 & 2.339 & 5.221 \\
\hline Top & 1.804 & 1.381 & 1.854 \\
\hline LogEC50 & 0.06057 & 0.06973 & 0.2272 \\
\hline \multicolumn{4}{|c|}{ 95\% Confidence intervals } \\
\hline Bottom & 11.02 to 19.31 & 12.17 to 22.00 & 40.50 to 62.43 \\
\hline Top & 84.49 to 92.07 & 88.87 to 94.67 & 87.52 to 95.31 \\
\hline LogEC50 & 0.5238 to 0.7783 & 1.291 to 1.584 & 1.531 to 2.486 \\
\hline EC50 & 3.340 to 6.002 & 19.55 to 38.38 & 33.99 to 306.2 \\
\hline \multicolumn{4}{|c|}{ Goodness of fit } \\
\hline R square & 0.979 & 0.9819 & 0.8256 \\
\hline
\end{tabular}

Figure 5: Inhibitory activity of different concentrations of valerian (Val), Melissa (Mel), and its combination on GABA Transaminase (GABA-T).

shock, and anxiogenic drugs have been shown to increase the efflux of glutamate as measured by microdialysis in vivo [34,37-41].

The role of GABA has long been regarded as central to the modulation of anxiety and this neurotransmitter system is the target of benzodiazepines and related drugs used to treat anxiety disorders. It has been estimated that at least one-third of all CNS neurons utilize GABA as their primary neurotransmitter, and GABA ergic inhibition is essential for maintaining a balance between neuronal excitation and inhibition [42]. A number of studies have indicated that relative to healthy controls, GABA levels in plasma and cerebrospinal fluid are lower in acutely depressed patients [43-45].

The glutamatergic system is increasingly regarded as a primary mediator of psychiatric pathology and, potentially, also a final common pathway for the therapeutic action of antidepressant agents [45].

Our experiment demonstrated that the Unpredictable Chronic Mild Stress (UCMS) animal model reduces brain levels of GABA while increasing the glutamate levels. MEL and VAL show different patterns of activity: MEL and VAL administered alone could not reduce in a statistical significant way, using this model, GABA stress induced levels; however, a combination treatment did. Remarkably, upon extract combination treatment, the brain level of GABA at the end of the period of stress was close to the basal values.

Regarding the glutamate brain levels, VAL given alone counteracts the increase of glutamate induced by stress, while MEL given alone is less effective. However, the combination of VAL and MEL reduced the glutamate brain levels significantly compared to VAL given alone. This demonstrates that MEL administered alone is insufficient to counteract stress-induced increase of glutamate, but in combination with VAL can significantly counteract this effect in the brain.

Many mechanisms could be involved in the GABAergic and glutamatergic regulation exerted by the two extracts. Various studies report that VAL could stimulate the GABA transmission and inhibit GABA receptors; it may also involve benzodiazepine-like mechanism of action [10,17-20]. Kennedy, et al. found that an acute administration of $600 \mathrm{mg}$ of MEL extract increased calmness and reduced alertness [24]. This pattern of mood modulation suggests the involvement of the GABAergic system in the MEL anxiolytic effects. A survey of ten anxiolytic botanicals was reported recently, and an extract of MEL was found to be the best inhibitor of in vitro GABA-T activity from rat brain [27]. Similarly, Awad, et al. [46] reported that MEL inhibits GABA-T, attributing this effect to rosmarinic acid, a major constituent of lemon balm. In our study, we confirmed that MEL is an inhibitor of GABA-T activity; however, this mechanism could be not sufficient to produce a significant effect in counteracting the stress-induced reduction of GABA levels.

With respect to the release of glutamate, we tested the hypothesis that the extracts in the study could act as agonists on mGluRs. In recent years, several studies have investigated the effects of VAL in the excitatory glutamate-mediated neurotransmission and showed that the extract of VAL and in particular valerenic acid are able to interact with Group I and Group II mGluRs, thus having calming and relaxing effects that may represent the main mechanism of action to explain the anxiolytic properties of this plant $[21,22,47,48]$.

In our study, VAL extract in presence of LCCG-I, a Group II metabotropic glutamate receptor agonist, shows a marked decrease in the binding at all tested concentrations. This effect was seen with L-AP4 at high concentration only. Our results confirm the hypothesis of VAL interaction with the presynaptic mGluRs, suggesting a possible mechanism by which VAL extracts counteract the excess of glutamate release induced by stress. On the other hand, the extract of MEL seems to have no detectable effect on these glutamate receptors.

\section{Conclusions}

Our results demonstrate that the combined mechanism of action of the two extracts contained in Songha ${ }^{\circledR}$ Night may induce a synergistic effect acting on two targets, inducing the normalization of the hyperactive excitatory brain system seen during stressful conditions: MEL-inhibits GABA-T activity and increases the levels of GABA, and VAL acts on Group II mGluRs and decreases the release of glutamate. Furthermore, the two extracts 
together exert a unique functional synergism leading to normalization of brain levels of GABA and glutamate altered by stress. This may explain the clinical effect of the two compounds on the reduction of anxiety and the consequent relief of sleep disturbances as reported in clinical studies performed with Songha ${ }^{\circledR}$ Night.

However, the exact mechanism involved in this action is complex and not yet fully understood and it will be the subject of future investigations.

\section{Conflict of Interest}

We wish to confirm that there has been no significant financial support for this work that could have influenced its outcome. Andrea Zangara has been a consultant to Ginsana SA.

\section{References}

1. Sateia MJ, Doghramji K, Hauri PJ, Morin CM (2000) Evaluation of chronic insomnia. An American Academy of Sleep Medicine review. Sleep 23: 243-308.

2. Ohayon M (2002) Epidemiology of insomnia: What we know and what we still need to learn. Sleep Med Rev 6: 97-111.

3. Shochat T, Umphress J, Israel AG, Ancoli Israel S (1999) Insomnia in primary care patients. Sleep 22: S359-S365.

4. Dinges D, Rogers N, Baynard MD (2005) Chronic sleep deprivation. In: Kryger MH, Roth T, Dement WC, Principles and Practice of Sleep Medicine. ( $4^{\text {th }}$ edn), Elsevier/Saunders, Philadelphia, 67-76.

5. Siobhan Banks, David F Dinges (2007) Behavioral and physiological consequences of sleep restriction. J Clin Sleep Med 3: 519-528.

6. Institute of Medicine (US) Committee on Sleep Medicine and Research Colten HR, Altevogt BM (2006) Sleep disorders and sleep deprivation: An Unmet Public Health Problem.

7. Holbrook AM, Crowther R, Lotter A, Cheng C, King D (2000) The diagnosis and management of insomnia in clinical practice: A practical evidence based approach. CMAJ 162: $216-220$.

8. Morin CM, Culbert JP, Schwartz SM (1994) Non pharmacological interventions for insomnia: A meta-analysis of treatment efficacy. Am J Psychiatry 151: 1172-1180.

9. Pearson NJ, Johnson LL, Nahin RL (2006) Insomnia, trouble sleeping, and complementary and alternative medicine: analysis of the 2002 national health interview survey data. Arch Intern Med 166: 1775-1782.

10. Houghton PJ (1999) The scientific basis for the reputed activity of valerian. J Pharm Pharmacol 51: 505-512.

11. Barnes PM, Powell Griner E, McFann K, Nahin RL (2004) Complementary and alternative medicine use among adults: United States, 2002. Adv Data 1-19.

12. Perry EK, Pickering AT, Wang WW, Houghton PJ, Perry NSL (1999) Medicinal plants and Alzheimer's disease: From ethnobotany to phytotherapy. J Pharm Pharmacol 51: 527-534.

13. Grieve M (1931) A modern herbal. Jonathan Cape, London.

14. Bartram T (1995) Encyclopaedia of herbal medicine. Grace Publishers, London.

15. Bisset NG, Wichtl M (1994) Herbal drugs. Medpharm, Stutt- gart.

16. Kommission E Monograph (1984) Melissenbla'tter. Bundesanzeiger.

17. Cavadas C, Araujo I, Cotrim MD, Amaral T, Cunha AP, et al. (1995) In vitro study on the interaction of Valeriana officinalis $L$. extracts and their amino acids on $\operatorname{GABA}(A)$ receptor in rat brain. Arzneimittelforschung 45: 753-755.

18. Bent S, Padula A, Moore D, Patterson M, Mehling W (2006) Valerian for sleep: A systematic review and meta-analysis. Am J Med 119: 1005-1012.

19. Miyasaka LS, Atallah AN, Soares BG (2006) Valerian for anxiety disorders. Cochrane Database of Systematic Reviews.

20. Khom S, Baburin I, Timin E, Hohaus A, Trauner G, et al. (2007) Valerenic acid potentiates and inhibits GABA receptors: molecular mechanism and subunit specificity. Neuropharmacology 53: 178-187.

21. Malva JO, Santos S, Macedo T (2004) Neuroprotective properties of Valeriana officinalis extracts. Neurotox Res 6: 131140.

22. Del Valle Mojica LM, Cordero Hernández JM, González Medina G, Ramos Vélez I, Berríos Cartagena N, et al. (2011) Aqueous and Ethanolic Valeriana officinalis extracts change the binding of ligands to glutamate receptors. Evidence-Based Complementary and Alternative Medicine 2011: 891819.

23. Kennedy DO, Wake G, Savelev S, Tildesley NT, Perry EK, et al. (2003) Modulation of mood and cognitive performance following acute administration of single doses of Melissa officinalis (Lemon balm) with human CNS nicotinic and muscarinic receptor-binding properties. Neuropsychopharmacology 28: 1871-1881.

24. Kennedy DO, Little W, Scholey AB (2004) Attenuation of laboratory-induced stress in humans after acute administration of Melissa officinalis (Lemon Balm). Psychosom Med 66: 607-613.

25. Domschke K, Zwanzger P (2008) GABAergic and endocannabinoid dysfunction in anxiety-future therapeutic targets? Curr Pharm Des 14: 3508-3517.

26. Ashton H, Young AH (2003) GABA-ergic drugs: Exit stage left, enter stage right. J Psychopharmacol 17: 174-178.

27. Awad R, Levac D, Cybulska P, Merali Z, Trudeau VL, et al. (2007) Effects of traditionally used botanicals on enzymes of the gamma-aminobutyric acid (GABA) system. Can J Physiol Pharmacol 85: 933-942.

28. Brambilla P, Perez J, Barale F, Schettini G, Soares JC (2003) GABAergic dysfunction in mood disorders. Mol Psychiatry $8: 715,721-737$.

29. Swanson CJ, Bures M, Johnson MP, Linden AM, Monn JA, et al. (2005) Metabotropic glutamate receptors as novel targets for anxiety and stress disorders. Nat Rev Drug Discov 4: 131-144.

30. Cerny A, Schmid K (1999) Tolerability and efficacy of valerian/lemon balm in healthy volunteers (a double-blind, placebo-controlled, multicentre study). Fitoterapia 70: 221-228.

31. Kennedy DO, Little W, Haskell CF, Scholey AB (2006) Anxiolytic effects of a combination of Melissa officinalis and Valeriana officinalis during laboratory induced stress. Phytother Res 20: 96-102.

32. Chen G, Henter ID, Manji HK (2010) Presynaptic glutamatergic dysfunction in bipolar disorder. Biol Psychiatry 67: 1007-1009.

33. Zarate C, Machado Vieira R, Henter I, Ibrahim L, Diazgra- 
nados N, et al. (2010) Glutamatergic Modulators: The Future of Treating Mood Disorders? Harv Rev Psychiatry 18: 293-303.

34. Musazzi L, Milanese M, Farisello P, Zappettini S, Tardito D, et al. (2010) Acute stress increases depolarization evoked glutamate release in the rat prefrontal/frontal cortex: The dampening action of antidepressants. PLoS One 5: e8566.

35. Ducottet C, Griebel G, Belzung C (2003) Effects of the selective nonpeptide corticotropin-releasing factor receptor 1 antagonist antalarmin in the chronic mild stress model of depression in mice. Prog Neuropsychopharmacol Biol Psychiatry $27: 625-631$.

36. Sherif F, Eriksson L, Oreland L (1992) Gamma-aminobutyrate aminotransferase activity in brains of schizophrenic patients. J Neural Transm Gen Sect 90: 231-240.

37. Bianchi L, Della CL, Tipton KF (1999) Simultaneous determination of basal and evoked output levels of aspartate, glutamate, taurine, and 4-aminobutyric acid during microdialysis and from superfused brain slices. J Chromatogr B Biomed Sci Appl 723: 47-59.

38. Bagley J, Moghaddam B (1997) Temporal dynamics of glutamate efflux in the prefrontal cortex and in the hippocampus following repeated stress: Effects of pretreatment with saline or diazepam. Neuroscience 77: 65-73.

39. Timmerman W, Westerink BH (1997) Brain microdialysis of GABA and glutamate: What does it signify? Synapse 27: 242-261.

40. Lowy MT, Wittenberg L, Yamamoto BK (1995) Effect of acute stress on hippocampal glutamate levels and spectrin proteolysis in young and aged rats. J Neurochem 65: 268-274.

41. Reznikov LR, Grillo CA, Piroli GG, Pasumarthi RK, Reagan LP, et al. (2007) Acute stress-mediated increases in extracellular glutamate levels in the rat amygdala: differen- tial effects of antidepressant treatment. Eur $\mathrm{J}$ Neurosci 25: 3109-3114.

42. Bloom FE, Iversen LL (1971) Localizing 3H-GABA in nerve terminals of rat cerebral cortex by electron microscopic autoradiography. Nature 229: 628-630.

43. Sanacora G, Mason GF, Rothman DL, Behar KL, Hyder F, et al. (1999) Reduced cortical gamma-aminobutyric acid levels in depressed patients determined by proton magnetic resonance spectroscopy. Arch Gen Psychiatry 56: 10431047.

44. Sanacora G, Gueorguieva R, Epperson CN, Wu YT, Appel $M$, et al. (2004) Subtype-specific alterations of gamma-aminobutyric acid and glutamate in patients with major depression. Arch Gen Psychiatry 61: 705-713.

45. Sanacora G, Treccani G, Popoli M (2012) Towards a glutamate hypothesis of depression: an emerging frontier of neuropsychopharmacology for mood disorders. Neuropharmacology 62: 63-77.

46. Awad RA, Muhammad T, Durst VL, Trudeau JT (2009) Arnason bioassay-guided fractionation of lemon balm (Melissa officinalis L.) using an in vitro measure of GABA transaminase activity. Phytother Res 23: 1075-1081.

47. Del Valle Mojica LM, Ayala Marín YM, Ortiz Sanchez CM, Torres Hernández BA, Abdalla Mukhaimer S, et al. (2011) Selective interactions of valeriana officinalis extracts and valerenic acid with $[3 \mathrm{H}]$ glutamate binding to rat synaptic membranes. Evidence-Based Complementary and Alternative Medicine 2011: 403591.

48. Del Valle Mojica LM, Ortíz JG (2012) Anxiolytic properties of Valeriana officinalis in the zebrafish: a possible role for metabotropic glutamate receptors. Planta Med 78: 17191724. 